Araştırma Makalesi/Research Article

\title{
Çanakkale İli Biga İlçesinde Uygulanan Arazi Toplulaştırma Çalışmaları, Üreticilerin Memnuniyet ve Bilinç Seviyelerinin Belirlenmesi
}

\author{
Tuğba Erenci $^{1^{*}} \quad$ Selma Kayalak ${ }^{1}$ \\ ${ }^{1}$ ÇOMÜ Ziraat Fakültesi, Tarım Ekonomisi Bölümü. 17100/Çanakkale \\ *Sorumlu Yazar: tugbaerenci@windowslive.com
}

Geliş Tarihi: 12.06 .2018

Kabul Tarihi: 06.12.2018

Öz

$\mathrm{Bu}$ araştırma, Çanakkale İli Biga İlçesinde uygulanan arazi toplulaştırma çalışmalarından, üreticilerin bilinç seviyelerinin ve memnuniyetlerinin belirlenmesi amacıyla, 2016 - 2017 yıllarında yürütülmüştür. Araştırmanın evrenini, Çanakkale İli Biga İlçesinde arazi toplulaştırmasına katılan çiftçiler oluşturmaktadır. Araştırmanın örneklemi ise Çanakkale İli Biga İlçesinde arazi toplulaştırmasına katılan 161 çiftçidir. Araştırmada çiftçilerin yaşları, eğitim durumu, arazi toplulaştırması öncesi ve sonrası, çiftçilerin arazi varlık durumları, arazi toplulaştırmasına katılım konusunda çiftçilerin istekleri ve toplulaştırmadan sonraki düşünceleri incelenmiştir. Toplulaştırma öncesine göre, uygulama sonrasında sulu arazi miktarı artarken, sulu arazi parsel sayısı, kuru arazi miktarı ve kuru arazi parsel sayısı azalmıştır. Çiftçilerin \% 88,3'ü arazi toplulaştırmasına istekliyken, uygulama sonrasında çiftçilerin \% 77,6'sının toplulaştırma konusundaki olumlu düşüncelerinde değişme olmadığı tespit edilmiş̦tir.

Anahtar Kelimeler: Çanakkale, Biga, Arazi toplulaştırması, Memnuniyet

\section{Detection of Satisfaction and Awareness Levels, Land Consolidation Practices in Province Çanakkale, Biga District \\ Abstract}

This research was carried out in 2016 - 2017 in order to determine the level of satisfaction and awareness of the producers of land consolidation studies applied in the province of Biga, Çanakkale. The universe of the research is the farmers who participated in the land consolidation in Biga, Çanakkale. The sample of theresearch is 161 farmersparticipating in thelandconsolidation in Biga, Çanakkale. Inthesurvey, ages of farmers, educational status, landownership status of farmers before and after land consolidation, farmers' willingness to participate in land consolidation and pos tconceptions were examined.

According to the pre-consolidation, after the implementation, while the number of irrigated area parcels, dry area and the number of parcels in dry areas decreased. While $88.3 \%$ of the farmers were eager for land consolidation, $78.9 \%$ of the farmers did not change their positive thoughts thinking about consolidation after the implementation.

Keywords: Çanakkale, Biga, Land Consolidation, Satisfaction

\section{Giriş}

Arazi toplulaştırılması, tarımsal üretimin arttırılması amacıyla, küçük parseller halinde birden fazla parçaya bölünmüș, değișik yerlere dağılmıș veya elverișsiz biçimde șekillenmiș arazilerin; modern tarım işletmeciliği esaslarına göre ve sulama hizmetlerinin getirilmesine en uygun bir şekilde birleştirilmesi, şekillendirilmesi ve düzenlenmesidir (Anonim, 2013). Ayrıca birim alandan azami verim elde etmek, işgücü verimliliğini arttırmak, çiftçinin hayat standardını yükseltecek bütün teknik, sosyal ve kültürel tedbirlerin alınmasıdır (Altıntaş ve Akçay, 2009).

Nüfusun artışına paralel olarak işlenebilir arazilerin artmaması neticesinde, toprak üzerindeki nüfus baskısı giderek artmaktadır. Artan nüfusun tarım dışı sektörlere çekilememesi ve diğer parçalanma nedenlerinden dolayı tarım işletmelerinin sahip olduğu araziler, sürekli parçalamakta ve ekonomik işletme büyüklüğünün altına düşmektedir (Ekinci, 2010). Tarım işletmelerinin arazi miktarındaki azlık ve mevcut arazilerin de birbirinden uzak olması, bu arazilerden istenilen üretim artışını sağlamaya engel olmaktadır (Bilgin, 2014). Bununla birlikte halen geçerli olan kiracılık, yarıcılık ve ortakçılık düzeni, ekonomik ve verimli tarım yapılmasını engellemektedir (Altıntaş, 2006). Bütün bu sorunlara çözüm bulabilmek için Gıda, Tarım ve Hayvancılık Bakanlığı onayıyla toplulaştırma çalışmaları yapılmaktadır. 
Bu araştırmada, Çanakkale İl Özel İdaresi'nin Çanakkale İli Biga İlçesinin, 10 köyüne ait 600 hektarlık alan da gerçekleștirilen toplulaştırma projesi kapsamında, üreticilerin arazi toplulaştırmayla ilgili bilinç ve memnuniyet seviyelerinin belirlenmesi amaçlanmıştır.

\section{Materyal ve Yöntem}

Araştırmanın materyali, Çanakkale ili Biga ilçesi Yeniçiftlik, Örtülüce, Kocagür, Tokatkırı, Geyikkırı, Karahamzalar, Karacaali, Adliye, Hacı Hüseyin Yaylası ve Çınarköprü köylerinde uygulanan arazi toplulaştırma çalışmalarıyla ilgili üreticilerle yapılan anket çalışmasıyla elde edilmiştir.

Araştırmanın örnek hacminin belirlenmesinde, sonlu popülasyonlarda varyans bilinmiyorsa kullanılan Oransal Örnekleme Yöntemi kullanılmıștır (Miran 2003). Söz konusu 10 köyde arazi toplulaştırma çalışmalarına katılan 4637 küçük aile işletmesi bulunmaktadır.

n= Örnek büyüklüğü,

$$
n=\frac{N p(1-p)}{(N-1) \sigma_{p}^{2}+p(1-q)}
$$

$\mathrm{N}=$ Populasyon büyüklüğü,

$\mathrm{p}=0,5$ tahmin oran 1 ,

$\sigma=$ oran varyans1, bulunmuştur.

Örnek hacmi yukarıdaki formülle \%99 güven aralığında ve \%10 hata payıyla 161 olarak

\section{Yöntem}

Araştırmada 161 üretici ile yüz yüze görüşülerek, arazi toplulaştırma çalışmaları hakkındaki memnuniyet düzeyleri hakkında görüşleri alınmıştır. Üreticiler ile yapılan görüșmelerde kullanılan anket formundan elde edilen verilerin sayısal ve oransal hesaplamaları yapılarak çizelgeler ile gösterimleri yapılmıştır.

\section{Bulgular v3e Tartıșma}

Biga Türkiye'nin Marmara Bölgesinin güneybatı bölümünde yer alan, Çanakkale iline bağlı bir ilçedir. Çanakkale İlinin yüz ölçümü bakımından 2. büyük ilçesidir. Biga, Çanakkale ekonomisinin lokomotifi konumundadır. 2 belde ve 108 köye sahip ilçede, toplam nüfus 2016 itibariyle 89853 ve ilçede toplam nüfusun \%40'ını (36 349) tarım nüfusunu oluşturmaktadır. Çanakkale ilinde mevcut tarım işletmelerinin \%20,52 (10 290)'si Biga ilçesinde tarımsal faaliyet göstermektedir. İlçe ekonomisinin temeli tarıma dayanmaktadır. Çanakkale genelinde üretilen bitkisel üretim değerinin $\% 22$ 's1 ve hayvansal üretim değerinin \%36's1, toplam tarımsal üretim değerinin ise \%25 Biga ilçesinde üretilmektedir. Yörenin verimli topraklarında buğday, pirinç, günebakan, baklagiller ve her türlü sebze meyve yetiştirilir (Anonim, 2016).

Çizelge 1. Çanakkale İl Özel İdaresi’nin 2005-2010 Yılları Arasında Tamamladığı Arazi Toplulaştırma Projeleri

\begin{tabular}{|l|r|r|l|l|}
\hline Köy Adı & \multicolumn{1}{l|l|}{$\begin{array}{l}\text { Uygulama } \\
\text { Yılı }\end{array}$} & $\begin{array}{l}\text { Onceki } \\
\text { Parsel } \\
\text { Sayıs }\end{array}$ & $\begin{array}{l}\text { Sonraki } \\
\text { Parsel } \\
\text { Sayısı }\end{array}$ & $\begin{array}{l}\text { Toplulaştır } \\
\text { ma } \\
\text { Oranı } \\
\text { \% }\end{array}$ \\
\hline H. Hüseyin Yaylası & $2005-2008$ & 437 & 366 & 16 \\
\hline Karacaali & $2005-2008$ & 444 & 265 & 40 \\
\hline Örtülüce 1 & $2006-2007$ & 677 & 384 & 43 \\
\hline Geyikkırı & 2007 & 201 & 138 & 23 \\
\hline Karahamzalar & 2007 & 383 & 294 & 30 \\
\hline Örtülüce 2 & 2007 & 307 & 214 & 36 \\
\hline Tokatkırı & $2007-2008$ & 764 & 489 & 44 \\
\hline Kocagür & $2007-2008$ & 1112 & 618 & 63 \\
\hline Yeniçiftlik & $2008-2009$ & 3114 & 1160 & 55 \\
\hline Çırnarköprü & $2009-2010$ & 394 & 177 & 33 \\
\hline Adliye & $2009-2010$ & 221 & 148 & 47 \\
\hline & TOPLAM & 8054 & 4253 & \\
\hline
\end{tabular}


Çizelge 1'de görüldüğü üzere, Yeniçiftlik Köyü arazi toplulaștırma öncesi parsel adedi 3114 iken proje sonrası 1160 adet olmuştur. Biga ilçesi şahıs işletmelerine ait tarım arazileri içinde toplulaştırma oranı \%63 olarak gerçekleşmiştir. Diğer taraftan Çınarköprü Köyündeki arazi toplulaştırması öncesi parsel adedi 394 iken proje sonrası 177 adet olmuştur ve toplulaştırma oranı $\% 55$ 'tir.Toplamda 8054 olan parsel sayısı 4253 parsele düşmüştür.

Araştırma kapsamında görüşülen çiftçilerin hepsi erkektir. Bunun nedeni kadın işletme sahipliğinin az olmasıdır.

Çizelge 2. Yaș ve Eğitim Durumu

\begin{tabular}{|l|r|r|l|r|r|}
\hline Yaş Grupları & Frekans & \% & Ĕgitim Durumu & Frekans & \multicolumn{1}{l|}{} \\
\hline $\mathbf{3 3 - 4 0}$ & 9 & 5,59 & Okur-Yazar & 3 & 1,86 \\
\hline $\mathbf{4 1 - 5 0}$ & 27 & 16,77 & İlkokul & 125 & $\mathbf{7 7 , 6 4}$ \\
\hline $\mathbf{5 1 - 6 0}$ & 42 & 26,09 & Ortaokul & 20 & 12,42 \\
\hline $\mathbf{6 1 - 7 0}$ & 62 & 38,51 & Lise & 11 & 6,83 \\
\hline $\mathbf{7 1 - 8 0}$ & 14 & 8,70 & Üniversite/Yüksekokul & 2 & 1,24 \\
\hline $\mathbf{8 1 ~ v e ~ u ̈ z e r i ~}$ & 7 & 4,35 & - & - & - \\
\hline Toplam & 161 & 100,00 & Toplam & 161 & 100,00 \\
\hline
\end{tabular}

Üreticilerin yaşları en az 34, en fazla 84'tür. Yaş ortalamasına bakıldığında ortalamanın 59,41 olduğu ve yaşlı grubunda yer aldığı görülmüştür. Araştırma alanında yer alan işletmelerdeki bireylerin büyük çoğunluğunun ilkokul $(\% 77,64)$ mezunu olduğu görülmüştür.

\section{İşletmelerin Arazi Varlığı}

Bu araştırmanın amacı arazi toplulaştırması olduğu için tarımsal yapı içinde arazi maliklerinin toplam arazi genişlikleri birincil olarak ele alınmıştır. Buna bağlı olarak tarımsal işletme büyüklükleri ve parsel sayıları incelenmiştir.

İşletme sahiplerinin toplulaştırma öncesi sulu arazi ortalaması 38,83 dekar ve kuru arazi ortalaması 53,29 dekardır. Arazi toplulaştırması sonrası kuru arazi miktarlarının düşüş gösterdiği ve sulu arazi miktarlarının arttığı görülmüştür. Toplulaştırma sonrası sulu arazi ortalaması 52,35 dekar ve kuru arazi ortalaması 40,11 dekarlık araziye sahiptir.

Çizelge 3. Arazi Toplulaştırması Öncesi ve Sonrası Sulu-Kuru Arazi Parsel Sayıları

\begin{tabular}{|c|c|c|c|c|c|c|c|}
\hline & Grup & Frekans & $\%$ & & Grup & Frekans & $\%$ \\
\hline \multirow{6}{*}{$\begin{array}{l}\text { Toplulaştırma } \\
\text { Öncesi Sulu } \\
\text { Arazi Parsel } \\
\text { Sayısı }\end{array}$} & $0-5$ & 141 & 87,58 & \multirow{6}{*}{$\begin{array}{l}\text { Toplulaştırma } \\
\text { Sonrası Sulu } \\
\text { Arazi Parsel } \\
\text { Sayısı }\end{array}$} & $0-5$ & 141 & 87,58 \\
\hline & $6-10$ & 11 & 6,83 & & $6-10$ & 15 & 9,32 \\
\hline & $11-15$ & 3 & 1,86 & & $11-15$ & 4 & 2,48 \\
\hline & 16-20 & 4 & 2,48 & & 16 ve üzeri & 1 & 0,62 \\
\hline & 21 ve üzeri & 2 & 1,24 & & - & - & \\
\hline & Toplam & 161 & 100,00 & & Toplam & 161 & 100,00 \\
\hline \multirow{6}{*}{$\begin{array}{l}\text { Toplulaştırma } \\
\text { Öncesi Kuru } \\
\text { Arazi Parsel } \\
\text { Sayısı }\end{array}$} & $0-5$ & 97 & 60,25 & \multirow{6}{*}{\begin{tabular}{|l} 
Toplulaştırma \\
Sonrası Kuru \\
Arazi Parsel \\
Sayısı \\
\end{tabular}} & $0-5$ & 147 & 90,74 \\
\hline & 6-10 & 46 & 28,57 & & $6-10$ & 11 & 6,79 \\
\hline & $11-15$ & 9 & 5,59 & & $11-15$ & 2 & 1,23 \\
\hline & $16-20$ & 5 & 3,11 & & 16 ve üzeri & 1 & 1,24 \\
\hline & 21 ve üzeri & 4 & 2,48 & & - & - & \\
\hline & Toplam & 161 & 100,00 & & Toplam & 161 & 100,00 \\
\hline
\end{tabular}

Arazi toplulaştırılması sonrasında parsel sayısındaki azalış dikkat çekicidir. Toplulaştırma çalışmalarında sulanan tarım bölgelerde 40 parsele kadar olan bölünmüş araziler, 20 parsele; sulanmayan tarım bölgesinde ise 30 parsele kadar çıkan araziler ise 18 parsele indirilmiştir. 


\section{Arazi Toplulaştırma Çalışmalarına Katılım Durumu}

Katılımcıların \%100'ü, projeden 1 yıl önce çalışmalara başlanacağının duyurulduğunu belirtmiştir. "Konu ile ilgili kurum tarafından bilgilendirme toplantısı yapıldı mı?" sorusuna katılımcıların \%98,76'sı evet cevabını verirken, \%1,24'ü hayır cevabını vermiştir. Ayrıca yapılan bilgilendirme toplantısına üreticilerin \%88,32'si katıldığını, \%11,18'i katılmadıklarını belirtmiştir. Katılımcıların \%87,58'inin istekli olduğu ve \%12,42'sinin istekli olmadığı görülmüştür.

\section{Arazi Toplulaştırması Konusunda Üreticilerin Bilinç ve Memnuniyet Seviyesi}

Üreticilere yöneltilen "Toplulaştırma kapsamında arazinize yapılan yenilikler nelerdir?" sorusuna arazi tesviyesi hariç diğer yeniliklerin yapıldığını belirtenlerin oran ortalaması \%87,68 iken, arazi tesviyesinin yapıldığını belirtenlerin oranı sadece $\% 22,36$ 'tür.

Çizelge 4.Toplulaştırma kapsamında arazinize yapılan yenilikler

\begin{tabular}{|l|r|r|r|r|r|}
\hline $\begin{array}{l}\text { Toplulaştırma kapsamında arazinize } \\
\text { yenilikler }\end{array}$ & yapılan & $\begin{array}{l}\text { Frekans } \\
\text { (evet) }\end{array}$ & $\begin{array}{l}\text { Frekans } \\
\text { (hayır) }\end{array}$ & $\begin{array}{l}\text { Evet } \\
\text { \% }\end{array}$ & \multicolumn{1}{l}{$\begin{array}{l}\text { Hayır } \\
\text { \% }\end{array}$} \\
\hline Arazi Tesviyesi & 36 & 125 & 22,36 & 77,64 \\
\hline Tarla İçi Drenajı & 111 & 50 & 68,94 & 31,06 \\
\hline Tarla Íçi Yol ve Tahliyesi & 150 & 11 & 93,17 & 6,83 \\
\hline Toprak Islahı Çalışmaları & 127 & 34 & 78,88 & 21,12 \\
\hline Su Kanalı & 157 & 4 & 97,52 & 2,48 \\
\hline Kanaletler(Küçük kanal, küçük suyolu) & 151 & 10 & 93,79 & 6,21 \\
\hline Borulu Şebekeler & 151 & 10 & 93,79 & 6,21 \\
\hline
\end{tabular}

Çizelge 5.Arazi Toplulaştırması Konusunda Üreticilerin Memnuniyet Seviyesi

\begin{tabular}{|c|c|c|c|c|c|}
\hline Memnuniyet Seviyesi & 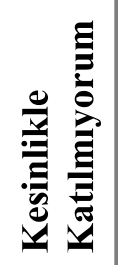 & 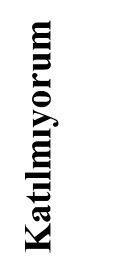 & 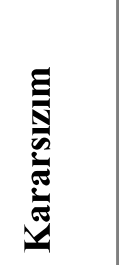 & 竞 & 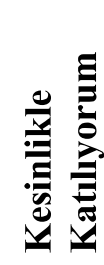 \\
\hline & $\%$ & $\%$ & $\%$ & $\%$ & $\%$ \\
\hline $\begin{array}{l}\text { 55. Toplulaştırma çalışmalarından önce verilen bilgiler } \\
\text { sizce yeterli oldu mu? }\end{array}$ & 4,35 & 4,35 & 18,63 & 31,06 & 41,61 \\
\hline $\begin{array}{l}\text { 56. Toplulaştırma projesi öncesinde parsel sayınızın } \\
\text { azalacağını biliyor muydunuz? }\end{array}$ & 0,62 & 1,86 & 3,11 & 43,48 & 50,93 \\
\hline $\begin{array}{l}\text { 57. Toplulaştırma projesi öncesinde olumlu yönde } \\
\text { arazinizde yenilikler olacağını düşünüyor muydunuz? }\end{array}$ & - & 3,11 & 13,04 & 44,72 & 39,13 \\
\hline $\begin{array}{l}\text { 58. Proje uygulamasından önce köyün ileri gelenlerinden } \\
\text { veya muhtarından fikir aldınız mı? }\end{array}$ & 6,21 & 5,59 & 11,80 & 39,13 & 37,27 \\
\hline $\begin{array}{l}\text { 59. Proje uygulamasından sonra çalışmalar hakkında } \\
\text { fikirleriniz olumsuz yönde oldu mu? }\end{array}$ & 18,63 & 24,22 & 31,06 & 13,66 & 12,42 \\
\hline $\begin{array}{l}\text { 60. Toplulasstırma öncesinde üreticiler olarak sizin } \\
\text { görüşleriniz dikkate alındı mı? }\end{array}$ & 11,80 & 6,21 & 23,60 & 27,33 & 31,06 \\
\hline $\begin{array}{l}\text { 61. Toplulaştırma sonucunda oluşan yeni parsellerin adaletli } \\
\text { bir şekilde dağıtıldığını düşünüyor musunuz? }\end{array}$ & 6,83 & 8,70 & 24,22 & 37,89 & 22,36 \\
\hline $\begin{array}{l}\text { 62. Toplulaştırma sonrasında size teslim edilen yeni } \\
\text { araziden daha fazla gelir elde ettiğinizi olduğunu düşünüyor } \\
\text { musunuz? }\end{array}$ & 4,35 & 6,21 & 16,77 & 33,54 & 39,13 \\
\hline $\begin{array}{l}\text { 63. Toplulaştırma sonrasında arazi değerinizde artış } \\
\text { olduğunu düşünüyor musunuz? }\end{array}$ & 4,97 & 3,73 & 8,70 & 24,84 & 57,76 \\
\hline 64. Toplulaştırma sonrası arazi kullanımınız kolaylaştı mı? & 1,24 & 1,24 & 3,73 & 26,09 & 67,70 \\
\hline
\end{tabular}




\begin{tabular}{|l|r|r|r|r|r|}
\hline 65. Toplulaştırma sonrası arazi sulamanız kolaylaşı mı? & 2,48 & 5,59 & 6,21 & 21,12 & $\mathbf{6 4 , 6 0}$ \\
\hline $\begin{array}{l}\text { 66. Toplulaştırma çalışmasını ekonomik yönden faydalı } \\
\text { buldunuz mu? }\end{array}$ & 1,24 & 1,86 & 3,11 & 28,57 & $\mathbf{6 5 , 2 2}$ \\
\hline $\begin{array}{l}\text { 67. Toplulaştırma çalışmasını sosyal yönden faydalı } \\
\text { buldunuz mu? }\end{array}$ & 1,24 & 3,11 & 1,86 & 31,68 & $\mathbf{6 2 , 1 1}$ \\
\hline $\begin{array}{l}\text { 68. Toplulaştırma sonrasında arazilerin çeşitli nedenlerle } \\
\text { yeniden parçalanacağını düşünüyor musunuz? }\end{array}$ & $\mathbf{5 4 , 1 4}$ & 30,43 & 6,21 & 3,11 & 3,11 \\
\hline $\begin{array}{l}\text { 69. Arazi Toplulaştırma çalışmalarını diğer üreticilere de } \\
\text { tavsiye edebilir misiniz? }\end{array}$ & 6,21 & 4,35 & 6,83 & 24,84 & $\mathbf{5 7 , 7 6}$ \\
\hline
\end{tabular}

Araştırmaya göre projeden önce toplulaştırma çalışmalarının olumlu olacağ $\breve{1}_{1}$ konusuna üreticilerin \%44,72'si katılmıștır. Araştırmaya konu olan bölgede köyün ileri gelenlerinin ve muhtarının fikrini katılımcıların \%39,13'ü aldığını belirtmişlerdir. Üreticilere yöneltilen "Toplulaştırma öncesinde üreticiler olarak sizin görüşleriniz dikkate alındı mı?" sorusuna, katılımcıların \%31,06'sı kesinlikle katıldıklarını belirtmişlerdir.

Arazi toplulaştırması sonucunda üreticilerin $\% 37,86$ 'u oluşan yeni parsellerin adaletli dağıtıldığını belirtmişlerdir. Toplulaştırma sonrasında arazi değerlerinin arttığını ifade edenlerin oranı \%57,76'dır. Toplulaştırma sonrası arazi kullanımının kolaylaştığı, sulamanın kolaylaştığı, ekonomik ve sosyal yönden faydalı bulunduğu sorularına sirasiyla $\% 67,70 ; \% 64,60 ; \% 65,22 ; \% 62,11$ 'dir.

Toplulaştırma sonrası arazilerin çeşitli nedenlerle tekrar parçalanacağına üreticiler \%54,14 oranla kesinlikle katılmadıklarını ifade etmişlerdir.

Katılımcıların \%57,76 arazi toplulaştırma çalışmalarını diğer üreticilere tavsiye ettiklerini ve $\% 6,21$ 'inin tavsiye etmediklerini belirtmişlerdir.

Çizelge 6. Arazi Toplulaştırma Çalışmalarının Tavsiye Edilmesinin Nedenleri

\begin{tabular}{|l|r|}
\hline \multirow{2}{*}{ Nedenler } & Evet \\
\cline { 2 - 2 } & $\%$ \\
\hline Parsel sayısının azalması & 84,47 \\
\hline Makine kullanımının kolaylaşması & 84,47 \\
\hline Tarla yollarının düzenlenmesi & 83,85 \\
\hline Arazi değerinin yükselmesi & 82,61 \\
\hline Sulamanın kolaylaşması & 87,47 \\
\hline
\end{tabular}

Katılımcılar; parsel sayısının azalması, makine kullanımının kolaylaşması, tarla yollarının düzenlenmesi, arazi değerinin yükselmesi, sulamanın kolaylaşması gibi nedenlerde arazi toplulaştırma çalışmalarını tavsiye etmişlerdir.

Katılımcıların \%9,94'ü gibi az sayıdaki kısmı; arazi kaybı, tarla yollarının dar olması, adaletsiz arazi dağıtımı, verilen sözlerin tutulmaması, istimlâk, arazi değerinin düşmesi, tesviyenin düzgün yapılmaması, yollara su taşıyor olması gibi nedenlerle arazi toplulaştırma çalışmalarını tavsiye etmemişlerdir.

Çizelge 7. Toplulaştırma Çalışmaları Sonrasındaki Fikir Değişimi Durumu

\begin{tabular}{|l|r|r|r|r|r|}
\hline $\begin{array}{l}\text { Toplulaştırma Çalışmaları Sonrasındaki Fikir } \\
\text { Değişimi Durumu }\end{array}$ & Frekans & \multicolumn{2}{l|l|l|}{$\begin{array}{l}\text { Oransal } \\
\%\end{array}$} & $\begin{array}{l}\text { Kümülatif } \\
\%\end{array}$ \\
\hline Evet (Olumluyken Olumsuz Oldu) & 36 & 22,36 & 22,36 & 22,36 \\
\hline Hayır (Olumluydu ve Değişmedi) & 125 & 77,64 & 77,64 & 100,00 \\
\hline Toplam & 161 & 100,00 & 100,00 & \\
\hline
\end{tabular}

Araştırma kapsamında sorulan fikir değişimi sorusuna üreticilerin \%77,64'ünün kararlarının olumlu olduğunu ve kararın toplulaştırma sonrasında da değişmediğini, \%22,36's1 ise olumlu düşünüyorken toplulaştırma çalışmalarından sonra fikirlerini olumsuz yönde değisstirdiklerini 
belirtmişlerdir. Üreticilerin arazi toplulaştırma konusunda memnun kalmamalarındaki en önemli faktör arazi tesviyesinin düzgün yapılmamış olmasıdır $(\% 77,64)$.

\section{Sonuç ve Öneriler}

Üreticilerin yaş durumu, eğitim durumu ve mesleki tecrübeleri incelendiğinde memnuniyet ve bilinç seviyeleri arasında bir ilişki bulunamamıştır.

Üreticiler, projeyi uygulayan kurum hakkında bilgi sahibi olmadıklarını söylemişlerdir. Kitle iletişim araçlarıyla yapılan bilgilendirme çalışmaları önemsenmemiştir.

Biga bölgesinde yapılan proje öncesinde toplam 8054 parsel sayısı çalışmalar sonucunda 4253 parsele indirilmiş ve kuru araziler ise proje kapsamında yapılan sulama çalışmaları sonucunda yaklaşık olarak \%53’ten \% $\%$ 'a düşmüştür. kalınmıștır.

Üretici görüşlerine göre, toplulaştırma çalışmalarında arazi tesviyesi konusunda eksik

Ankete katılan üreticilerin yaklaşık \%58'i arazi toplulaştırma çalışmalarını diğer üreticilere tavsiye etmiş ve muvafakat vermelerinin yararlarına olacaklarını söylemişlerdir. Toplulaştırmayı tavsiye etmeyenlerin oranı ise yaklaş1k \%10'dur.

Toplulaştırma projelerinin daha başarılı olabilmesi için üreticilerin bu konuda bilinçlendirilmesi önem arz etmektedir. Üretici eğitim ve yayım programlarında bu konuya yer verilmesi gerekli görülmektedir. Üretici eğitimlerinde konunun işlenmesinin yanında, araştırma sonuçlarının kanıtlandığı örnek proje sahalarının üreticilere gösterilerek toplulaştırmanın gerçek anlamıyla tanıtılması ve katılımın arttırılmasında yarar görülmektedir (Altıntaş, 2009).

Yapılan arazi toplulaştırma projelerinin yürütülmesinden sorumlu bakanlık Gıda, Tarım ve Hayvancılık Bakanlığı olmasına rağmen birbirinden farklı mevzuatlara göre projelerin yapılması, karışıklığa sebebiyet vermektedir. Bu nedenle arazi toplulaştırma projelerinde bir standart yakalanması amacıyla arazi toplulaştırması yapmak isteyen bütün kurum ve kuruluşların kullanacağı ortak bir mevzuatın hazırlanması gerekmektedir.

Devlet $\mathrm{Su}$ İşlerinin sulama göleti çalışmasıyla başlayan toplulaştırma faaliyetlerinde, toplulaştırılacak arazilerin tarımsal etütleri ile birlikte uygun üretim deseni oluşturulmalı ve toplulaştırma faaliyeti sürerken çiftçilere bu üretim deseni ile ilgili bilgi ve teknik destek sağlanmalıdır (Anonim, 2013).

Not: Bu makale ÇOMÜ Fen Bilimleri Enstitüsü Tarım Ekonomisi Anabilim Dalı Öğrencisi Tuğba Erenci'nin "Çanakkale İli Biga İlçesinde Uygulanan Arazi Toplulaştırma Çalışmaları, Üreticilerin Memnuniyet ve Bilinç Seviyelerinin Belirlenmesi” isimli Yüksek Lisans tez çalışmasından türetilmiştir. Bu çalışma, II. Çanakkale Tarım Sempozyumu (14-15 Aralık 2017) Bildiri Özetleri kitabında yayınlanmıştır.

\section{Kaynaklar}

Anonim, 2013. Fırat Kalkınma Ajansı, Arazi Toplulaștırma Faaliyetleri, 2013.

Anonim, 2016. https://canakkale.tarim.gov.tr/Menu/13/Brifingler (Erişim Tarihi: 21.11.2017)

Altıntaş, G., 2006, Tokat İli Erbaa Ovasında Arazi Toplulaştırması Yapılmış Alanlardaki Tarım İşletmelerinin Ekonomik Analizi ve Optimum Üretim Planlarının Belirlenmesi Üzerine bir Araştırma. Gaziosmanpaşa Üniversitesi Fen Bilimleri Enstitüsü, Yayınlanmamış Doktora Tezi, Tokat.

Altıntaş, G., Akçay Y., 2009, Arazi Toplulaştırma Uygulamalarında Üreticilerin Toplulaştırmaya Bakış Açılarını Etkileyen Faktörler (Tokat-Erbaa Örneği), Tarım Ekonomisi Dergisi, 15(1):35-45

Bilgin, C., 2014, Trakya Bölgesindeki Uygulanan Arazi Toplulaştırmasının Çiftçiler Üzerindeki Etkinliğinin İrdelenmesi, Namık Kemal Üniversitesi, Biyosistem Mühendisliği Anabilim Dalı, Yüksek Lisans Tezi, Tekirdağ.

Ekinci, K., 2010, Arazi Toplulaştırması Konusunda Çiftçi Davranışlarının Belirlenmesi (Bafra Ovası Örneği), Gazi Osman Paşa Üniversitesi, Fen Bilimleri Enstitüsü, Tarım Ekonomisi Anabilim Dalı, Yüksek Lisans Tezi, Tokat.

Miran, B., 2003. Temel İstatistik, Ege Üniversitesi Basımevi, Bornova, İzmir. 